\title{
Obituary
}

\section{Solomon C Goldberg, PhD}

Neuropsychopharmacology (2008) 33, 3252; doi: $10.1038 / n p p .2008 .130$

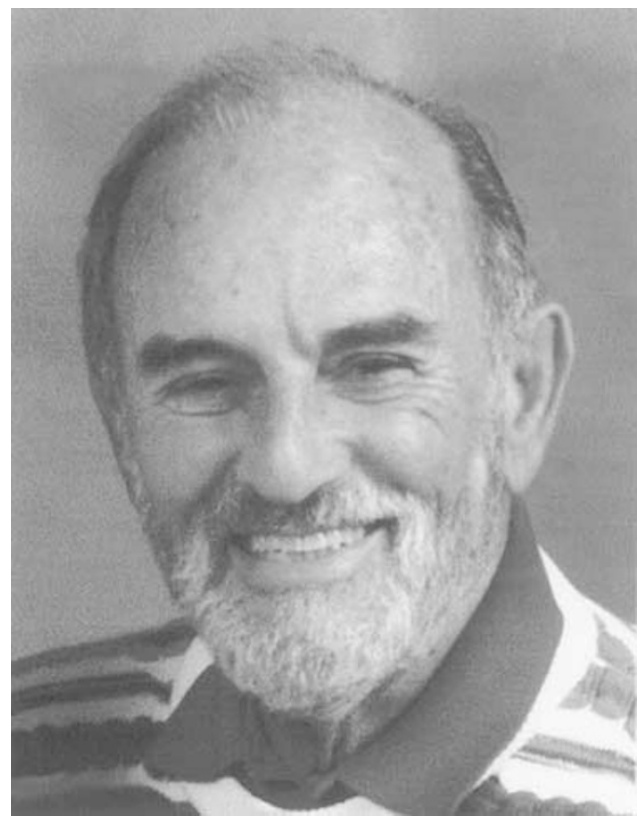

Solomon C Goldberg died in December 2007. He was 83 years old and had retired 10 years earlier. He fit into retirement easily, shifted from singles to doubles in tennis, and enjoyed an active life with his wife Pat. His research career and contributions helped forge the field of clinical psychopharmacology clinical trials.

Sol was born in Annapolis, Maryland, and was an Army Air Force gunner in World War II, flying 35 missions. He was 18 years old when he was drafted and said that, at the time, he felt no danger. He received his $\mathrm{PhD}$ from Catholic University in 1952 in social psychology.

He joined the Psychopharmacology Service Center (PSC) at NIMH in 1960 and became the third member of the triumvirate with Jonathan Cole and Gerry Klerman designing the study comparing then-new neuroleptics to placebo in schizophrenia-published in the Archives of General Psychiatry in 1964. That study provides a key citation for the short-term efficacy of neuroleptics in schizophrenia. A 6-month study provided evidence for continued improvement over time, A 2-year study (with Jerry Hogarty and me) demonstrated the efficacy of antipsychotic medication in preventing relapse and was the first to study the interaction of medication and psychosocial treatments in schizophrenia. His work also presaged the current concern with personalized treatment-then described as 'the right drug for the right patient.' The models used focused on characterization of symptom patterns, but Sol would have been right at home in the current efforts.

$\mathrm{He}$ was also instrumental in developing the first clinical trials in anorexia nervosa-now working with Katherine Halmi, Regina Kaspar, and Elke Eckert. He brought methodological rigor to a new area, by designing multicenter trials that provided the first comparative data regarding pharmacologic treatment in anorexia nervosa.

Sol was Executive Secretary of the Psychopharmacology Research Review Committee and Assistant Chief of the Psychopharmacology Research Branch at NIMH. He was an ACNP Fellow and Assistant Secretary Treasurer and VicePresident of our society. His other honors included the Hofheimer Prize for Research from the American Psychiatric Association in 1969.

On leaving NIMH, Sol became Professor of Psychiatry at the Medical College of Virginia (MCV). A new group of investigators benefited from his expertise. Robert Hamer, Professor of Psychiatry and Biostatistics at the University of North Carolina, was one of them. Bob remembers that 'Sol served as my mentor in psychiatric research and helped turn a quantitative psychologist and statistician toward a productive and fulfilling career in psychiatric and other medical research. Without him, I wouldn't be where I am today.' Another MCV colleague was S Charles Schulz, Chair of the Department of Psychiatry at University of Minnesota. Chuck expressed his gratitude to Sol by a commemorative event at an early meeting of the International Congress On Schizophrenia Research.

Sol had a wry and wicked sense of humor. In one cartoon on his office bulletin board, two scientists in laboratory coats face one another holding fencing foils. The caption reads: It's agreed, the survivor will be first author. Solomon did not wear a laboratory coat and he was generous to a fault with authorship. His CV reflects that generosity and colleagues that he encouraged will remember his support, encouragement, and intellectual stimulation.

$\mathrm{He}$ is survived by his wife, D Patterson (Pat) Goldberg, three children from his first marriage, Jan Kaplan, Nancy Heyman, and Richard Goldberg and four grandchildren.

My personal professional debt to him is great. He was my mentor, invited me to my first ACNP meeting, and nominated me for membership. I learned of his death as I was leaving for the 2007 meeting. Preparing this obituary is my last thank you.

Nina R Schooler ${ }^{1}$

${ }^{1}$ Professor of Psychiatry, State University of New York Downstate Medical Center, Washington, DC, USA 